УДК 338.484.2

08.00.00 Экономические науки

КОМПЛЕКСНЫЙ АНАЛИЗ СТРАТЕГИЧЕСКИХ ЗАЖИМОВ ЭКОНОМИЧЕСКОГО РАЗВИТИЯ МОРСКОГО ПЛЯЖНОГО ТУРИЗМА В КРАСНОДАРСКОМ КРАЕ

Федянина Юлия Сергеевна аспирант,

Кубанский государственный технологический университет, Краснодар, Россия

В статье проводится анализ турпотока российских граждан за рубеж, а также на отечественные курорты, в частности, Краснодарского края. Выделяются критерии при выборе туристом места для отдыха, на основании которых проводится оценка конкурентоспособности пляжного отдыха на АзовоЧерноморском побережье, сформирована основная региональная проблема развития морского пляжного туризма. Проведен обширный анализ частных проблем и ограничений, выделенных в блоки (финансово-экономические, технолого-экологические, институциональные, маркетинговые), предлагается их комплексное решение

Ключевые слова: КОНКУРЕНТОСПОСОБНОСТЬ, ТУРПОТОК, КАЧЕСТВО ТУРИСТСКИХ УСЛУГ, БЕЗОПАСНОСТЬ ТУРИСТОВ, РАЗВИТИЕ ПЛЯЖНЫХ ТЕРРИТОРИЙ
UDC 338.484 .2

Economics

THE COMPLEX ANALYSIS OF STRATEGIC BLOCKS OF ECONOMIC DEVELOPMENT OF SEA BEACH TOURISM IN THE KRASNODAR REGION

Fedyanina Yulia Sergeevna postgraduate student

Kuban State Technological University, Krasnodar, Russia

The article deals with the analysis of Russian tourists coming abroad and to Russian resorts, particular, to the Krasnodar region. The criteria of choosing of recreation places is delivered, according to it the assessment of competitiveness of beach rest on the Azov and Black Sea coast is given. The main regional problems of seacoast beach resort development were worked out. The article presents a vast analysis of special problems and limitations, that are involved in groups (financeeconomic, technological and ecological, institutional, marketing). The author gives the complex solution to these problems

Keywords: COMPETITIVENESS, TOURISTS, QUALITY OF SERVICE FOR TOURISTS, TOURISTS SAFETY, DEVELOPMENT OF BEACH TERRITORIES

DOI: $10.21515 / 1990-4665-122-051$

Согласно индексу конкурентоспособности сектора путешествий и туризма 2015 года, опубликованного аналитической группой Всемирного экономического форума, Россия относится к числу стран со стабильными показателями роста индустрии туризма и занимает 45 место в рейтинге, поднявшись на 18 позиций по сравнению с 2013 годом (индекс составляется каждые два года). [7] Однако в то время когда доля туризма в мировой структуре ВВП составляет почти 10\%, в России на отрасль туризма приходится всего лишь 1,5 \% ВВП. [8] Доля туризма в ВРП Краснодарского края в 2014 году составила 14,2\%.

Туристская отрасль страны неразрывно связана с мировой туристской отраслью. По данным Росстата в 2014 году выезд граждан Российской Фе- 
дерации с целью туризма за пределы страны снизился на 3,7 \% и составил 17611,6 тыс. человек (в 2013 году - 18 291,7 тыс. чел., в 2012 году - 15 332,1 тыс. чел.). В 10-ке наиболее популярных направлений первые места заняли Турция, Египет и Греция (таблица 1) . [9]

Таблица 1 - Выезд российских граждан за рубеж с целью туризма, в том числе по наиболее популярным направлениям, в динамике 2012-2014 годы (по данным Росстата)

\begin{tabular}{|c|c|c|c|c|c|c|c|c|c|c|c|}
\hline Страна & $\begin{array}{l}2009, \\
\text { тыс. } \\
\text { чел. }\end{array}$ & $\begin{array}{l}2010, \\
\text { тыс. } \\
\text { чел. }\end{array}$ & $\begin{array}{c}\text { Темп } \\
\text { при- } \\
\text { роста } \\
2010 / \\
2009, \\
\%\end{array}$ & $\begin{array}{l}2011, \\
\text { тыс. } \\
\text { чел. }\end{array}$ & $\begin{array}{c}\text { Темп } \\
\text { при- } \\
\text { роста } \\
2011 / \\
2010, \\
\%\end{array}$ & $\begin{array}{l}2012, \\
\text { тыс. } \\
\text { чел. }\end{array}$ & $\begin{array}{c}\text { Темп } \\
\text { при- } \\
\text { роста } \\
2012 / \\
2011, \\
\%\end{array}$ & $\begin{array}{l}\text { 2013, } \\
\text { тыс. } \\
\text { чел. }\end{array}$ & $\begin{array}{c}\text { Темп } \\
\text { при- } \\
\text { ро- } \\
\text { ста, } \\
2013 / \\
2012, \\
\%\end{array}$ & $\begin{array}{l}2014, \\
\text { тыс. } \\
\text { чел. }\end{array}$ & $\begin{array}{c}\text { Темп } \\
\text { при- } \\
\text { ро- } \\
\text { ста, } \\
2014 / \\
2013, \\
\%\end{array}$ \\
\hline Германия & 363,3 & 470,7 & 29,6 & 702,3 & 49,2 & 713,1 & 1,5 & 830,9 & 16,5 & 820,1 & $-1,3$ \\
\hline Греция & 282,3 & 386,7 & 37,0 & 612,5 & 58,4 & 690,4 & 12,7 & 1175,6 & 70,3 & 1016,1 & $-13,6$ \\
\hline Египет & 1615,4 & 2198,3 & 36,1 & 1452,8 & $-34,0$ & 1906,6 & 31,2 & 1909,2 & 0,1 & 2565,7 & 34,4 \\
\hline Испания & 296,3 & 411,4 & 38,8 & 645,3 & 56,9 & 792,1 & 22,7 & 1012,8 & 27,9 & 982,3 & $-3,0$ \\
\hline Италия & 336,1 & 451,5 & 34,3 & 571,6 & 26,6 & $\begin{array}{l}570,8 \\
\end{array}$ & $-0,1$ & 725,8 & 27,2 & 747,4 & 3,0 \\
\hline Кипр & 155,1 & 234,3 & 51,1 & 323,6 & 38,1 & 404,7 & 25,1 & 579,7 & 43,2 & 549,2 & $-5,3$ \\
\hline Китай & 999,2 & 1440,4 & 44,2 & 1502,3 & 4,3 & 1328,9 & $-11,5$ & 1067,5 & $-19,7$ & 766,3 & $-28,2$ \\
\hline ОАЭ & 214,3 & 286,9 & 33,9 & 394,6 & 37,5 & 549,4 & 39,2 & 653,4 & 18,9 & 597,4 & $-8,6$ \\
\hline Таиланд & 233,1 & 264,0 & 13,3 & 780,2 & 195,5 & 885,1 & 13,4 & 1035,0 & 16,9 & 933,8 & $-9,8$ \\
\hline Турция & 1964,9 & 2367,6 & 20,5 & 2681,7 & 13,3 & 2516,1 & $-6,2$ & 3078,6 & 22,4 & 3278,4 & 6,5 \\
\hline Итого & 6460,0 & 8511,8 & 31,8 & 9666,9 & 13,6 & 10357,2 & 7,2 & 12068,5 & 16,5 & 12256,7 & 1,6 \\
\hline $\begin{array}{l}\text { Всего по } \\
\text { всем } \\
\text { странам }\end{array}$ & 9542,1 & 12605,1 & 32,1 & 14495,9 & 15,0 & 15332,1 & 5,8 & 18291,7 & 19,3 & 17611,6 & $-3,7$ \\
\hline
\end{tabular}

В 2015 году по-прежнему наблюдается динамика снижения выезда российских граждан за границу. Так, за 9 месяцев 2015 года количество выехавших за пределы страны с целью туризма составило 9 995,5 тыс. человек, что на 31 \% меньше, чем за аналогичный период предыдущего года (14 559,2 тыс. человек). Так же сокращается численность выехавших российских граждан по таким популярным направлениям как Турция (на 21 \%), Египет (на 17 \%) и Греция (на 48\%). [9] Прогнозные данные по турпотоку на 2016 год представлены предварительными показателями в виде увеличения положительной динамики развития внутреннего туризма страны на $15 \%$. [10] 
По результатам анализа можно сделать вывод, что снижение туристических поездок граждан за границу могло произойти по одному или нескольким из предложенных факторов: политических (риск террористической активности, войны), экономических (нехватка денежных средств, страх потерять работу) и стихийных (землетрясение, наводнение). Сокращение туристского спроса российских граждан на международные туристские поездки с 2014 года по настоящее время показывают, что выездной туризм в России переживает некоторый кризис, связанный как с внешними санкциями, так и нестабильной политической ситуацией в странах Африки и Ближнего Востока, у россиян растёт интерес к отечественным курортам.

Влияние вышеуказанных факторов, в том числе прекращение туристического взаимодействия между Россией и Турцией, Египтом в виду политических событий, а также падение рубля по отношению к ведущим иностранным валютам - евро и доллару, переориентировало туристский спрос. Это способствовало перераспределению турпотока в другие страны (Греция, Израиль, Таиланд, Тунис, и другие), а также повышению спроса на российские курорты - Республику Крым и Краснодарский край.

По данным министерства курортов, туризма и олимпийского наследия Краснодарского края в текущем году в регионе наблюдается увеличение туристов на 6 \% (2016 г. - 8,7 млн., аналогичный период 2015 г. 8,2 млн.). Помимо очевидных эффектов от увеличения турпотока на курортах региона (увеличение занятости населения, развитие сопутствующих сфер: торговля, сфера услуг, транспорт, медицина) ожидается толчок развития малого (среднего) бизнеса, в частности в сфере строительства гостиниц и иных средств размещения, что положительно скажется на политике ценообразования и позволит получить дополнительные налоговые поступления в бюджет.

Вероятнее всего, переориентация туристов на фоне сложившейся си- 
туации на мировых политических и экономических аренах с внешних направлений на внутренние будет проходить скачкообразно. Поэтому местным курортам региона необходимо сосредоточиться на основных конкурентных позициях, таких как выгодное географическое положение, разнообразные природно-климатические условия и ландшафт, целебные источники минеральной воды и лечебной грязи. К сожалению, указанные преимущества позволяют привлечь, но не всегда могут удержать туриста на местном курорте.

По результатам анализа выделены основные критерии выбора туристом места для отдыха:

$\checkmark$ соотношение цены и качества отдыха;

$\checkmark$ чистота моря и качество пляжа;

$\checkmark$ безопасность отдыха;

$\checkmark$ общая атмосфера отдыха и туризма (сервис, развлечения).

Низкий уровень развития туристской индустрии отечественных курортов в сочетании с усиливающейся агрессивной конкуренцией зарубежных формирует основную региональную проблему развития АзовоЧерноморских курортов Краснодарского края - низкую конкурентоспособность, не позволяющую удовлетворить растущий спрос туристов на качественный и доступный отдых, наряду с опережающим ростом зарубежных курортов.

Проведем анализ основных проблем, способствующих сдерживанию экономического развития морского пляжного туризма в Краснодарском крае.

1. Финансово-экономические

Основным фактором, выбранным для проведения анализа, является стоимость туров (пляжный отдых) на курортах Краснодарского края и в ряде зарубежных стран (Турция, Китай, Кипр, Греция). В результате ана- 
лиза данных с сайта lkim.ru выявлено, что при раннем бронировании стоимость туров в высокий сезон с авиаперелетом на 7 дней для 2-х человек составляет в среднем 126,7 тыс. руб. На курортах Краснодарского края без авиаперелета стоимость проживания и питания составляет 104,4 тыс. руб.

Анализируя стоимость проезда на курорты Краснодарского края, например, приобретая билеты (на примере стоимости билетов с сайтов: avia.yandex.ru; flytourist.ru; aviasales.ru; avia.aviamonitor.ru) более чем за 9 месяцев до отдыха (в ноябре 2015 года на август 2016 года), то перелет на 2-х человек (туда/обратно) составит: Новосибирск-Сочи-Новосибирск (без пересадок) 46,0 тыс. руб., Новосибирск-Анапа-Новосибирск (без пересадок) 43,6 тыс. руб., Владивосток-Сочи-Владивосток (с 2 пересадками) от 66,5 тыс. руб., Владивосток-Анапа-Владивосток (с 2 пересадками) от 76,0 тыс. руб.

Очевидно, что одним из основных сдерживающих факторов отдыха на курортах региона является высокая цена на авиаперелет из разных регионов России. Решением вопроса может стать реализация мер государственной политики по вопросу снижения стоимости тарифов. Альтернативным способом снижения транспортной составляющей может стать формирование чартерных рейсов крупными игроками турбизнеса.

Более того, существует проблема соотношения цены и качества при предоставлении услуг по размещению отдыхающих. В большей степени это касается средств размещения, не прошедших классификацию, а значит не имеющих соответствующую категорию, определяющую набор требований к предоставляемым услугам.

Отсутствие действенных рычагов управления в отношении неорганизованного сектора средств размещения создает основу для недобросовестной конкуренции со стороны частных гостиниц, что противоречит требованиям законодательства. [1] Зачастую правообладатели малых 
средств размещения снимаются с налогового учета и предоставляют гостиничные услуги по договорам найма жилых помещений, тем самым скрывая реально полученные доходы. [6]

Данные факты, во-первых, подрывают доверие отдыхающих к курортам Краснодарского края, негативно отражаясь на общем впечатлении об отдыхе и, как следствие, на конкурентоспособности региона, а, вовторых, образуют "выпадающие" доходы бюджета, которые в год от индивидуальных средств размещения составляют порядка $40 \%$ в общем объеме, при этом налоговые поступления составляют лишь 13\%. [5,6]

2. Технолого-экологические

Зачастую развитие прибрежной курортной инфраструктуры в виде строительства санаторно-курортных и гостиничных предприятий, объектов общественного питания, развлекательных учреждений опережает возможности морской рекреационной зоны. Наблюдается рост числа отдыхающих в выходные и праздничные дни, что увеличивает нагрузку на пляжи.

Сложившаяся ситуация в пик сезона на Черноморском и частично на Азовском побережье Краснодарского края приводит к переуплотнению отдыхающих на пляжах более чем в 2-3 раза. Наименьшую нагрузку испытывают пляжи, которые принадлежат ведомственным организациям санаторно-курортного комплекса и пляжи детских здравниц. Согласно законодательству, площадь допустимой нормы на 1 человека должна состав-

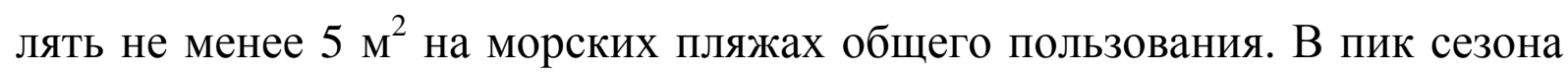
число единовременных посетителей на муниципальных пляжах составляет

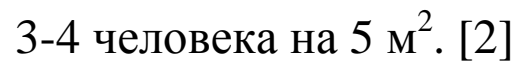

Указанная проблема осложняется существенным волновым воздействием на пляжные территории. Пляжи являются естественными образованиями, препятствующими разрушению суши волнами. Однако не все пляжи имеют достаточную устойчивость для обеспечения волногашения. 
В результате складывается ситуация нехватки берегозащитных сооружений, вследствие чего происходит размыв и сокращение ширины пляжа.

Другим ограничением является ухудшение санитарного состояния моря в виду климатических условий (повышение температуры), приходящихся на июль-август месяцы - периода образования и цветения морской водоросли Zostera marina (Камка). Осложняют ситуацию инфраструктурные проблемы, связанные с недостаточной системой водоотведения и мощностью очистных сооружений, нехваткой глубоководных выпусков в Mope.

\section{3. Институциональные}

Общественные отношения в области туристской деятельности регулируются большим количеством нормативных документов, но в совокупности данные правовые акты не исключают возможность различного понимания заложенных в них правовых требований. Результатом становятся нарушения законодательства в различных областях деятельности, связанных с предоставлением услуг на пляжах.

При проведении мониторинга отдельных пляжных территорий Азово-Черноморского побережья Краснодарского края с использованием методов наблюдения и опроса было выявлено, что чаще всего встречаются нарушения в области санитарно-эпидемиологического законодательства при продаже продуктов питания [3], правил розничной продажи алкогольной и спиртосодержащей продукции, в области природоохранного законодательства, в области технического регулирования использования аттракционной техники, законодательства о животном мире.

Некоторые нарушения являются следствием недостаточного правового регулирования сферы, как правило, на федеральном уровне. Так, ситуация в области технического регулирования использования аттракционной техники сложилась в результате пробелов правового регулирования 
данной сферы в виде отсутствия единых обязательных требований к техническому состоянию и безопасной эксплуатации аттракционной техники.

Еще одной острой проблемой, не позволяющей развиваться пляжным территориям Азово-Черноморского бассейна, стало заключение договоров водопользования в целях рекреации с любым лицом, которое выиграет конкурс на его заключение. В результате, складывается ситуация, при которой правообладатели пляжных территорий не имеют возможности своим территориям придать статус пляжа. Данная проблема наносит серьезный ущерб курортам Краснодарского края как материальный, так и имиджевый.

Результаты проведенного анализа можно представить в виде блоксхемы, отражающей основные проблемы, препятствующие развитию пляжных курортов Краснодарского края.

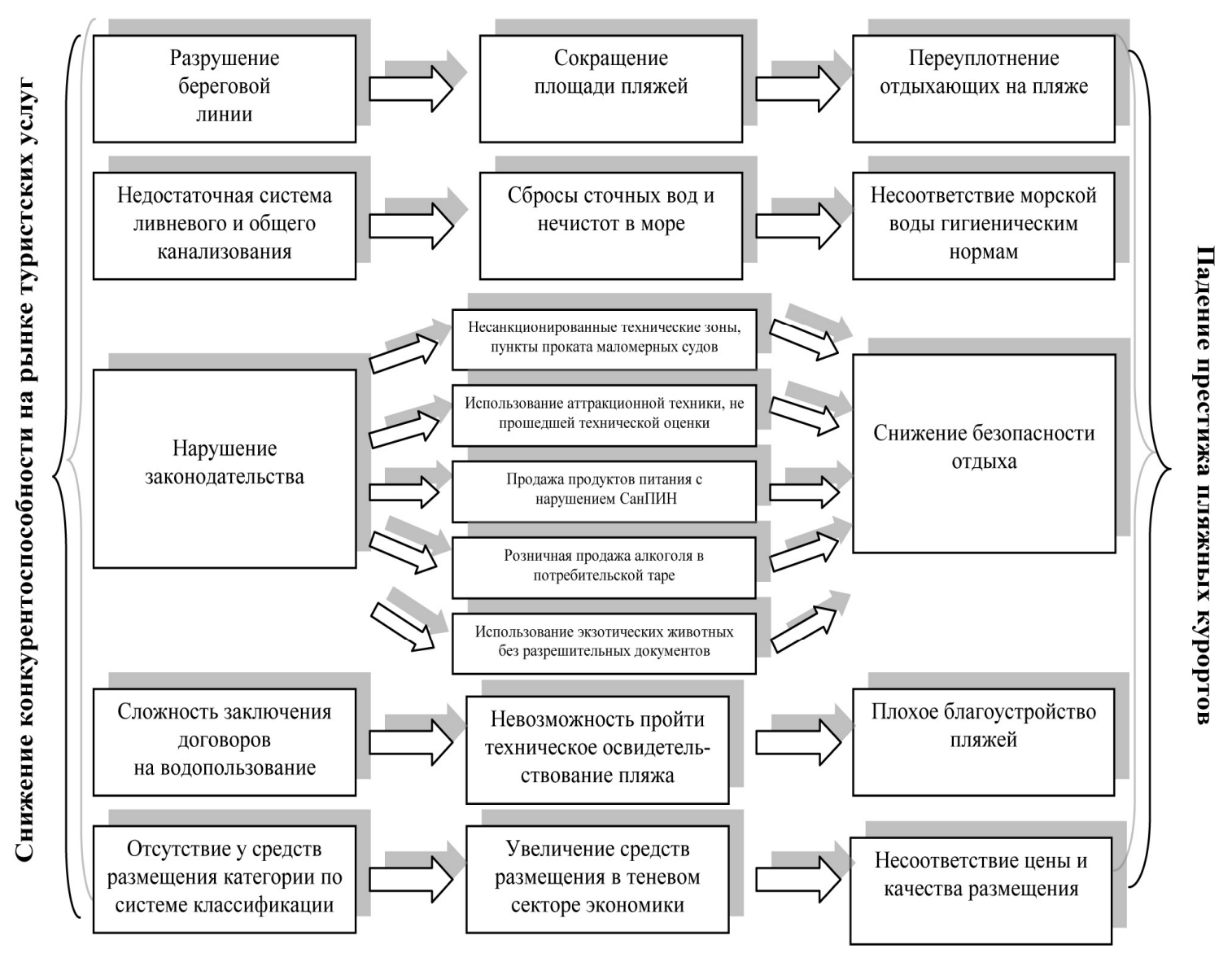




\section{4. Маркетинговые}

Одним из значимых факторов при выборе места отдыха является общая атмосфера отдыха и туризма курортных территорий. Единый архитектурный облик, красота окружающей природной среды, комфортные условия проживания, качественный сервис, а также дополнительные развлечения и экскурсии - основные составляющие данной атмосферы.

К примеру, набор услуг, входящих в стоимость тура на зарубежные или отечественные курорты, разный. Отели в Турции предлагают питание формата "шведский стол" по системе "все включено" и "ультра все включено" с разнообразным количеством блюд и напитков, которая действует круглосуточно. В стоимость входит также пользование пляжем и пляжными принадлежностями, бассейном и водными горками, турецкой баней, беспроводным интернетом на всей территории отеля, спортивными и детскими площадками, игровыми комнатами, тренажерным залом. На территории отеля также функционирует дискотека, проходят ежедневные анимационные развлекательные программы для взрослых и детей. Для сравнения, на курортах в странах Азии (Таиланд, Китай, Вьетнам и др.) в стоимость тура, помимо проживания, включается только завтрак, практически нет анимации.

Стараясь соответствовать высоким стандартам отдыха на зарубежных курортах, курорты Краснодарского края предлагают отели, работающие по системе "все включено" и подходящие для семейного пляжного отдыха. Однако большинству отелей региона необходимо усиливать работу по расширению ассортимента услуг и повышению качества обслуживания.

Выделенные факторы позволяют определить, что позиционирование курортных услуг должно быть разработано на основе целевого сегментного спроса с учетом конкурентных преимуществ и уникальности предо- 
ставляемых услуг. Краснодарский край, обладая необходимыми природными факторами, может дать туристу больше, чем зарубежные курорты. Всевозможные виды туризма и отдыха в сочетании с лечением на базе уникальных природных лечебных ресурсов, а также живописные пейзажи и разнообразный ландшафт в сочетании с богатым историческим наследием - основные конкурентные преимущества региона.

Развить и преумножить указанные преимущества, ликвидировать сложившиеся проблемные вопросы в отрасли, тем самым стимулировав ее, возможно путем внедрения новейших методик и стандартов развития, опираясь на положительный опыт зарубежных стран. Данное развитие возможно путем привлечения государственных инвестиций (развитие инфраструктуры пляжей), денежных средств частных инвесторов (развитие сопутствующей инфраструктуры) при использовании механизмов программно-целевого подхода и обязательной экспертной оценки принимаемых инициатив и качества выполнения плановых задач. Главными условиями расширения участия частного капитала в инфраструктурных проектах является предоставление государственных гарантий и обеспечение благоприятного делового климата.[4]

Очевидно, для того чтобы обеспечить долгосрочный рост туристской отрасли, необходимо новое комплексное решение, которое бы позволило обеспечить современное конкурентоспособное предложение. Таким решением может стать принятие долгосрочной Стратегии развития пляжных курортов Краснодарского края - комплекса скоординированных и объединенных единым замыслом правовых, политических, организационных, социально-экономических, информационных и иных мер, направленных на создание благоприятных условий для надежного существования и устойчивого развития сферы курортов и туризма. Результаты проведенного исследования позволяют сформулировать основные направления Стра- 
тегии для целей государственной регулятивной политики:

1) позиционирование курортов Краснодарского края как курортов с определенной тематической направленностью, которые наряду с пляжными услугами способны предложить различные виды отдыха и развлечений, с учетом существующих конкурентных преимуществ каждой территории;

2) целевая сегментация пляжных территорий (возрастная, ценовая и другие), которая позволит получать туристу полноценную информацию о планируемом отдыхе по соотношению "цена-качество";

3) расширение транспортной доступности курортных территорий, в том числе повышение комфортности на железнодорожном и автотранспорте, усиление пропускной способности путем налаживания взаимодействия с крупнейшими авиакомпаниями (чартерные рейсы);

4) повышение уровня сервисных услуг, предоставляемых на пляжных территориях, включая гостиничный и ресторанный комплекс, сферу развлечений;

5) благоустройство курортных городов, включая состояние пляжей, коммунальной инфраструктуры, обеспечение безопасности отдыха.

\section{Список использованных источников}

1. Конституция Российской Федерации, часть 1 статьи 8, часть 2 статьи 34.

2. СанПиН 4060-85, утвержденный Главным государственным санитарным врачом СССР от 26 декабря 1985 г.

3. Постановление Законодательного Собрания Краснодарского края от 22 октября 2014 года № 1289-П "О повышении качества услуг предоставляемых на пляжах, и обеспечении безопасности людей на водных объектах в Краснодарском крае".

4. Полиди А.А., Романец И.И. Повышение инвестиционной привлекательности региона как важнейшая государственная задача: проблемы и направления (на примере Краснодарского края) // Политематический сетевой электронный научный журнал Кубанского государственного аграрного университета (Научный журнал КубГАУ). - 2012 - №77(03).

5. Полиди А.А., Федянина Ю.С. Методический подход к управлению развитием горноклиматического курортного кластера в Краснодарском крае // Политематический сетевой электронный научный журнал Кубанского государственного аграрного университета (Научный журнал КубГАУ). - 2015 - №09(113). 
6. Федянина Ю.С. Классификация гостиниц и иных средств размещения как механизм эффективного управления сферой туризма // Интегрированные коммуникации в спорте и туризме: образование, тенденции, международный опыт. Материалы всероссийской научно-практической конференции с международным участием (14-15 апреля 2016 г.). - 2016. - Часть 2.

7. http://gtmarket.ru/news/2015/05/07/7152

8. http://www.vestifinance.ru/articles/61224

9. http://www.russiatourism.ru/contents/statistika/statisticheskie-pokazatelivzaimnykh-poezdok-grazhdan-rossiyskoy-federatsii-i-grazhdan-inostrannykhgosudarstv/kolichestvo-grazhdan-rossiyskoy-federatsii-vyekhavshikh-za-rubezh/

10. https://regnum.ru/news/cultura/2157258.html

\section{References}

1. Konstitucija Rossijskoj Federacii, chast' 1 stat'i 8, chast' 2 stat'i 34.

2. SanPiN 4060-85, utverzhdennyj Glavnym gosudarstvennym sanitarnym vrachom SSSR ot 26 dekabrja $1985 \mathrm{~g}$.

3. Postanovlenie Zakonodatel'nogo Sobranija Krasnodarskogo kraja ot 22 oktjabrja 2014 goda № 1289-P "O povyshenii kachestva uslug predostavljaemyh na plja-zhah, i obespechenii bezopasnosti ljudej na vodnyh ob\#ektah v Krasnodarskom krae".

4. Polidi A.A., Romanec I.I. Povyshenie investicionnoj privlekatel'-nosti regiona kak vazhnejshaja gosudarstvennaja zadacha: problemy i napravlenija (na primere Krasnodarskogo kraja) // Politematicheskij setevoj jelektronnyj nauchnyj zhurnal Kubanskogo gosudarstvennogo agrarnogo universiteta (Nauchnyj zhurnal KubGAU). - 2012 - №77(03).

5. Polidi A.A., Fedjanina Ju.S. Metodicheskij podhod k upravleniju razvitiem gornoklimaticheskogo kurortnogo klastera v Krasnodarskom krae // Politematicheskij setevoj jelektronnyj nauchnyj zhurnal Kubanskogo gosudarstvennogo agrarnogo universiteta (Nauchnyj zhurnal KubGAU). - 2015 - №09(113).

6. Fedjanina Ju.S. Klassifikacija gostinic i inyh sredstv razmeshhenija kak mehanizm jeffektivnogo upravlenija sferoj turizma // Integrirovannye kommunikacii v sporte i turizme: obrazovanie, tendencii, mezhdunarodnyj opyt. Materialy vserossijskoj nauchno-prakticheskoj konferencii s mezhdunarodnym uchastiem (14-15 aprelja 2016 g.). - 2016. - Chast' 2.

7. http://gtmarket.ru/news/2015/05/07/7152

8. http://www.vestifinance.ru/articles/61224

9. http://www.russiatourism.ru/contents/statistika/statisticheskie-pokazatelivzaimnykh-poezdok-grazhdan-rossiyskoy-federatsii-i-grazhdan-inostrannykhgosudarstv/kolichestvo-grazhdan-rossiyskoy-federatsii-vyekhavshikh-za-rubezh/

10. https://regnum.ru/news/cultura/2157258.html 